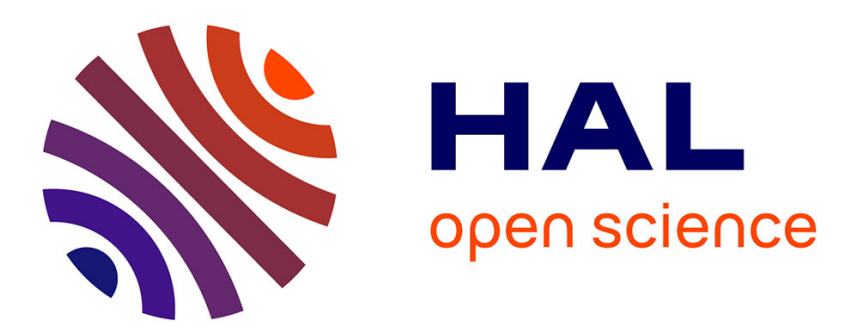

\title{
A critical analysis of plane shear tests under quasi-static and impact loading
}

Feifei Shi, R Merle, B Hou, Jiagui Liu, Yu Long Li, Han Zhao

\section{To cite this version:}

Feifei Shi, R Merle, B Hou, Jiagui Liu, Yu Long Li, et al.. A critical analysis of plane shear tests under quasi-static and impact loading. International Journal of Impact Engineering, 2014, 74, pp.107-119. 10.1016/j.ijimpeng.2014.06.012 . hal-01137374

\section{HAL Id: hal-01137374 \\ https://hal.science/hal-01137374}

Submitted on 30 Mar 2015

HAL is a multi-disciplinary open access archive for the deposit and dissemination of scientific research documents, whether they are published or not. The documents may come from teaching and research institutions in France or abroad, or from public or private research centers.
L'archive ouverte pluridisciplinaire HAL, est destinée au dépôt et à la diffusion de documents scientifiques de niveau recherche, publiés ou non, émanant des établissements d'enseignement et de recherche français ou étrangers, des laboratoires publics ou privés. 


\title{
A critical analysis of plane shear tests under quasi-static and impact loading
}

\author{
F.F. Shi ${ }^{1,2}$, R. Merle ${ }^{2}$, B. Hou ${ }^{1}$, J.G. Liu ${ }^{2}$, Y.L. Li $^{1}$ H. Zhao ${ }^{2 *}$
}

\author{
${ }^{1}$ School of Aeronautics, Northwestern Polytechnical University, 710072 Xi' an, China \\ ${ }^{2}$ Laboratoire de Mécanique et Technologie, ENS-Cachan/CNRS-UMR8535/Université Paris 6, \\ 61 avenue du président Wilson, 94235 Cachan cedex, France \\ * Correspondence to zhao@lmt.ens-cachan.fr
}

Keywords: Plane shear test, sheet metals, transient effect, cumulated Eulerian strain, SHPB.

\begin{abstract}
This paper presents an extensive investigation of the real testing conditions of plane shear tests under quasi-static as well as impact loading. In particular, it aims at analyzing the role played by the empirical corrective coefficients commonly used in this kind of tests. For this purpose, a complete numerical model including not only specimen but also clamping device is built. Compared with usual simulations of only a shear specimen used to establish these corrective coefficients, the proposed complete numerical model permits to evaluate the influence of clamping device on the distribution of stress and strain fields. It shows that there are only limited effects under static loading, except for the early stage of loading (elastic part) where the stiffness of clamping device has to be taken into account. Under dynamic loading, a similar conclusion as the static case has been made. However, the transient effect due to the wave propagation within clamping pieces is rather important before an equilibrium state is reached. Numerical results indicate also that the shear loading on the specimen is mainly guided by the compressive wave in the massive clamping pieces, and the shear wave propagation inside the shear area is negligible. Besides, the way to calculate the equivalent strain from experimentally measured displacement is discussed. Eulerian cumulated strain, which is the default large strain definition in most commercial codes, should be used instead of the idealized small strain shear assumption. Finally, this work indicates that when the average value of equivalent stress in the whole shear area and cumulated Eulerian strain are used, commonly used corrective coefficients are no longer needed.
\end{abstract}

\section{Introduction}

Plane shear test is a complementary tool to the standard tensile tests for sheet metals. It can be used to verify or identify the plastic criterion of sheet metals. The shear test permits also to realize large strain loading (till 80\%) while the tensile test fails to attain such a strain level because of geometric instability. The pioneer work in this domain was due to Iosipescu (1967)[1] who introduced the in-plane single shear fixture for sheet metals under quasi-static loading. Such a fixture was afterwards applied to polymer testing [2] and composites testing [3]. The well-known Arcan fixture [4] to generate in plane combined tension-shear was also quite close to this basic concept. A double plane shear test was reported in the literature in order to increase the stability of 
clamps [5].

Under dynamic loading, shearing tests were initially performed by Campbell and Ferguson (1970)[6]. They put a double-notched specimen directly in contact with an input Hopkinson bar and an output Hopkinson tube. However, a small double-notched specimen (gage length of $0.8 \mathrm{~mm}$ ) was used because of the small size of Hopkinson bars. It leads to an important error due to the non-homogeneous shear strain and also to the severe plastic deformation of the specimen supports. Modifications of the specimen geometry in order to reduce testing error was also reported [7] but with a limited improvement because the gage length is fixed.

In order to overcome this difficulty and to adopt a bigger specimen as used in most quasi-static cases, an additional co-axis clamping device is designed and placed in between a large diameter Hopkinson bar system. This technique was initially reported by Klepaczko et al.[8] and Gary and Nowacki[9] with respectively $30 \mathrm{~mm}$ and $40 \mathrm{~mm}$ diameter aluminum bar. This new technique offered rather good result provided that there is no impedance jump between clamping device and the Hopkinson bars and the wave dispersion effect is well taken into account in the data processing. Even larger system (60 mm diameter Hopkinson bar+clamping device) was also reported and it is proven that the plane wave assumption is still valid in this case[10]. However, with this new possibility of shear specimen geometry, it is still necessary to respect the limitation of the thickness/width ratio as well as width/length ratio of the shear area to prevent the buckling and instabilities [11]. Finally, the specimen geometry with $3 \mathrm{~mm}$ shear area was chosen in all aforementioned studies but a quasi-homogeneous state is not achieved yet.

Rusinek and klepaczko[12] performed a numerical analysis of the shear area to evaluate the homogeneous state level of the strain and stress fields in the shear area and found that they were not as homogeneous as expected. The non-homogeneous strain field was also experimentally proven by the successive digital image correlation measurement [13]. Besides, this simulation showed a significant gap between the prescribed constitutive law and the stress-strain relation obtained from simulated forces and displacements. Thus, coefficients (which is a function of the shear strain level) based on numerical simulations were proposed to fill in the gaps in stress as well as the strain. Such a concept of corrective coefficients is still used nowadays[14].

Nevertheless, such a 'state-of-art' is not satisfactory for many reasons. Actually, the numerical reference is a model with only a shear specimen. The stiffness of the clamping device is not taken into account, especially for the impact loading where the transient effect in the clamping device is not clear at all. Another possible discussion lies in the usual formulas relating forces and displacement to the shear stress and strain, especially under large strain. The present paper aims at a more complete analysis of the experimental conditions of this plane shear test. After a brief 
description of the plane shear testing arrangement as well as the commonly used formulas for stress/strain calculations, a complete numerical model (clamps + specimen) is proposed to evaluate the influence of the stiffness of the clamps in quasi-static and impact loading cases. An analysis of large strain deformation is also developed and it leads to the natural cancellation of corrective coefficients of strain.

\section{In-plane double shear tests}

\subsection{Basic testing arrangement}

The double plane shear device is composed of two coaxial pieces made of high strength steel with a double-notched specimen. The inner rectangular part of the specimen is clamped by the inner coaxial part with griping teeth aligned on the border of the shear area. The two external rectangular parts of the specimen are clamped by the external coaxial pieces with griping teeth as well. When the two coaxial pieces move relatively, the two rectangular zones (width $l$ ) between inner and external coaxial pieces are sheared (Fig. 1).
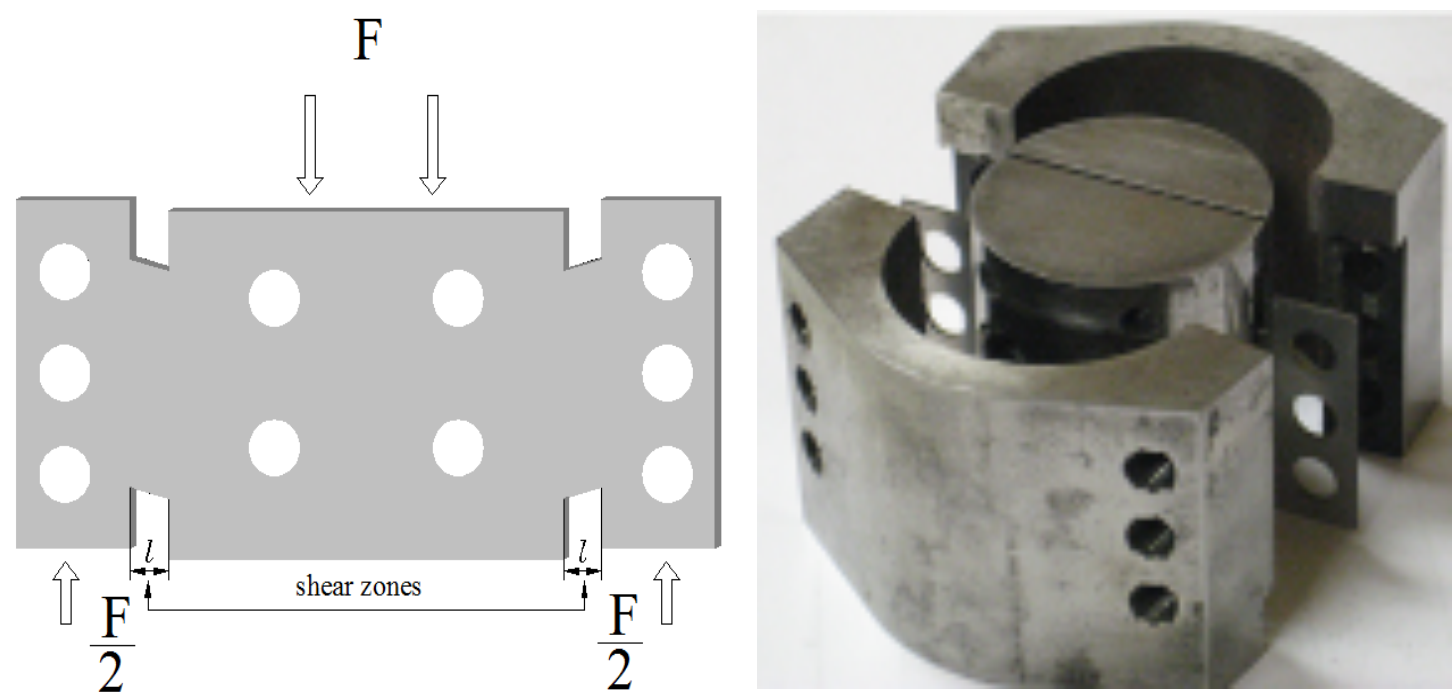

Fig. 1. Double shear specimen and clamping device

Quasi-static tests can be simply performed by putting the clamped specimen into a classical hydraulic testing machine. Dynamic tests can be realized by placing the clamped specimen in between the two Hopkinson pressure bars. It is of course necessary to ensure that the inner and external clamping pieces have the same acoustical impedance that equals to the pressure bar's impedance to avoid spurious oscillations. In particular, the studied device is designed for aluminum bars with a diameter of $60 \mathrm{~mm}$. Thus, the overall specimen size (Fig. 1, left) is of $60 \mathrm{~mm}$ long and $30 \mathrm{~mm}$ high. The clamping pieces have a length of $40 \mathrm{~mm}$. Technical details can be found in (Merle, 
2006)[15]. The schematic drawing of the whole system of impact testing is shown in Fig. 2.

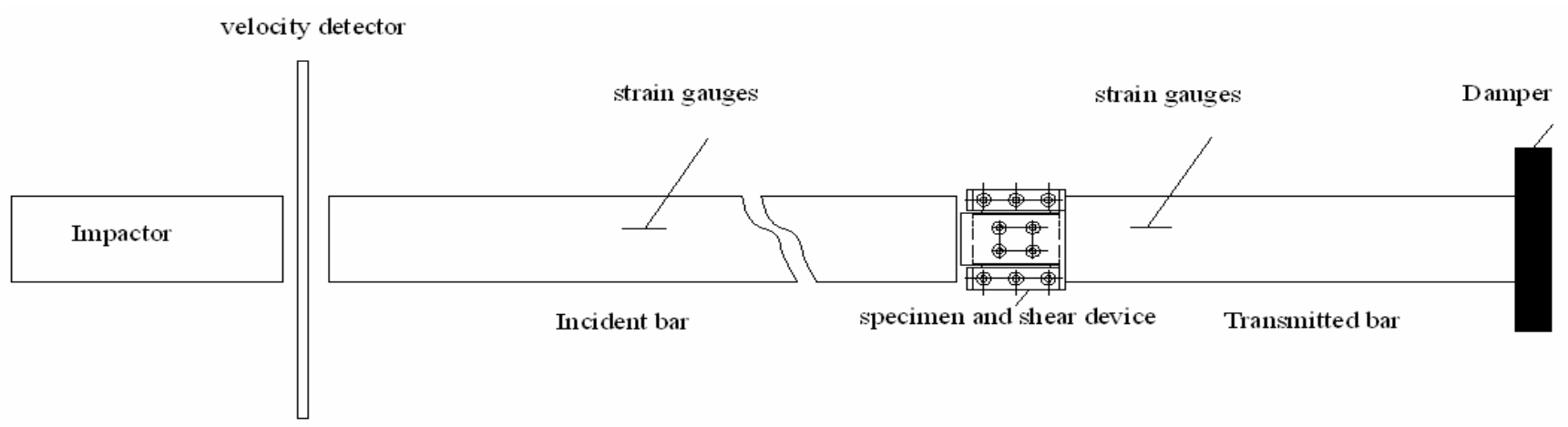

Fig. 2. Schematic drawing of Hopkinson bar and clamping device

With Hopkinson pressure bar system, the forces and the velocities are calculated from the recorded incident, reflected and transmitted waves profiles $\varepsilon_{\mathrm{i}}(\mathrm{t}), \varepsilon_{\mathrm{r}}(\mathrm{t}), \varepsilon_{\mathrm{t}}(\mathrm{t})$ by following equation (1) $[16]$.

$$
\begin{array}{ll}
\mathrm{F}_{\text {input }}(\mathrm{t})=\mathrm{S}_{\mathrm{B}} \mathrm{E}\left(\varepsilon_{\mathrm{i}}(\mathrm{t})+\varepsilon_{\mathrm{r}}(\mathrm{t})\right) & \mathrm{V}_{\text {input }}(\mathrm{t})=\mathrm{C}_{0}\left(\varepsilon_{\mathrm{i}}(\mathrm{t})-\varepsilon_{\mathrm{r}}(\mathrm{t})\right) \\
\mathrm{F}_{\text {ouput }}(\mathrm{t})=\mathrm{S}_{\mathrm{B}} \mathrm{E} \varepsilon_{\mathrm{t}}(\mathrm{t}) & \mathrm{V}_{\text {ouput }}(\mathrm{t})=\mathrm{C}_{0} \varepsilon_{\mathrm{t}}(\mathrm{t})
\end{array}
$$

where $\mathrm{S}_{\mathrm{B}}, \mathrm{E}$ and $\mathrm{C}_{0}$ are respectively the bar's cross-sectional area, Young's modulus, and the elastic wave speed.

Basic measurements of such a test are then the force $\mathrm{F}$ and the relative displacement $\mathrm{d}$ (see also Fig. 3).

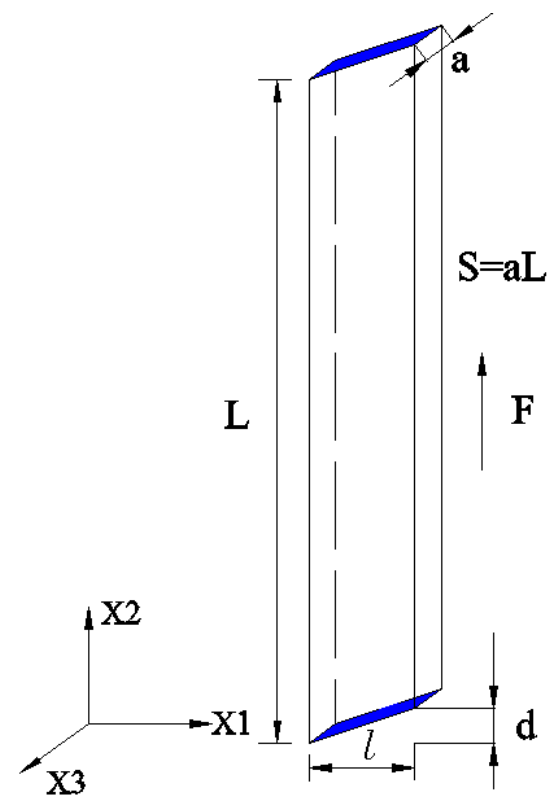

Fig. 3. Simple plane shear test

Idealized shear state is commonly assumed in the treatment of plane shear tests [6-9] and it leads to strain and stress states as the following: 


$$
\varepsilon=\frac{1}{2}\left[\begin{array}{lll}
0 & \gamma & 0 \\
\gamma & 0 & 0 \\
0 & 0 & 0
\end{array}\right] \quad \sigma=\left[\begin{array}{lll}
0 & \tau & 0 \\
\tau & 0 & 0 \\
0 & 0 & 0
\end{array}\right]
$$

where $\gamma=\mathrm{d} / l$ is the engineering shear strain and $\tau$ is the shear stress. Classical equivalent strain and stress can be calculated with the measured displacement $\mathrm{d}$ and force $\mathrm{F}$ if von Mises criterion is assumed (Eqs. $3 \& 4$ ).

$$
\begin{aligned}
& \varepsilon_{e q}=\frac{\mathrm{d}}{l \sqrt{3}} \\
& \sigma_{e q}=\tau \sqrt{3}, \tau=\frac{F}{S} .
\end{aligned}
$$

Typical testing result can be found in aforementioned studies and in our work on a SMAT treated steel sheet in particular [17]. The basic material parameters of specimen and clamps are listed in Table 1.

\begin{tabular}{ccccc}
\hline \multirow{2}{*}{$\begin{array}{c}\text { Components } \\
\end{array}$} & $\begin{array}{c}\text { Young's } \\
\text { Modulus (GPa) }\end{array}$ & Poission's Ratio & $\begin{array}{c}\text { Yield Stress } \\
(\mathrm{MPa})\end{array}$ & $\begin{array}{c}\text { Ultimate stress } \\
(\mathrm{MPa})\end{array}$ \\
\hline Specimen & 210 & 0.3 & 290 & 810 \\
clamps & 210 & 0.3 & -- & -- \\
\hline
\end{tabular}

Table 1. Material parameters of specimen and clamps

\subsection{Difficulties and improvement}

Taking our experimental setup as an example where the shear area width is $3 \mathrm{~mm}$, a simple numerical simulation of a rectangular shear specimen with $3 \mathrm{~mm}$ width and the length varying from $20 \mathrm{~mm}$ to $120 \mathrm{~mm}$ is performed to evaluate the plane shear testing condition. The numerical model is constructed in ABAQUS/standard code with the 8-node linear brick elements with reduced integration and hourglass control (C3D8R). The use of 3D brick element is motived by the small element size compared to the thickness of specimen (especially in the complete numerical model with clamping devices). Another reason is to avoid simplified large strain treatments in some type of shell elements used in explicit version. The clamping boundary condition is applied to one edge 
of rectangular shear specimen, while a velocity of $0.001 \mathrm{~mm} / \mathrm{s}$ was imposed on the nodes of the opposite edge. The constitutive relation used in this simulation is extracted from testing curve of SMAT treated steel (Fig. 4) [17].
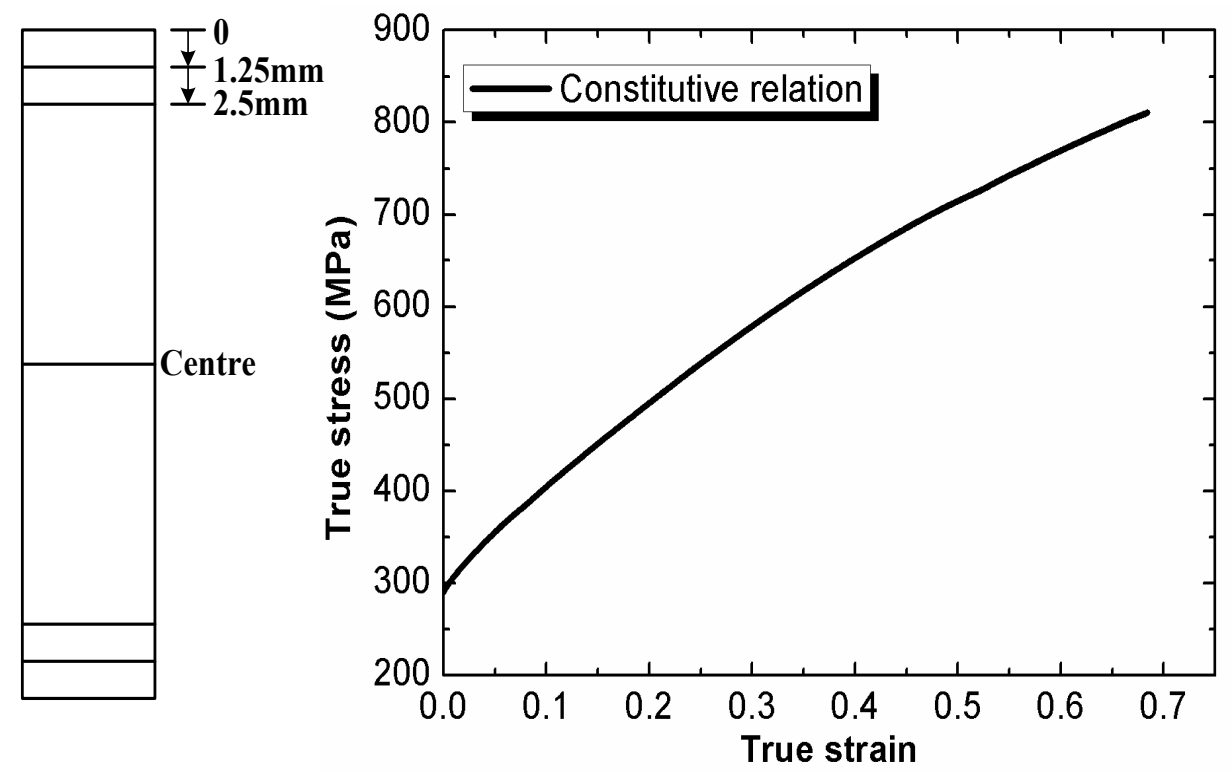

Fig. 4. Schema of the specimen (Left) and prescribed constitutive relation (Right)

It is noted that the real testing condition is not the idealized shear condition as shown in Eq. 2 because lateral motion of the coaxial clamping devices is not possible. There are then more and more tension components when the strain increases with the commonly used a strain tensor definition as that in a FEM code (detailed theoretical analysis can be found in section 4). Fig. 5 depicts the average value of all the elements of different components of stress and strain tensors (noting that stress and strain in $\mathrm{x}$ direction is normally in compression but depicted in positive here for easier comparison with y direction and the engineering shear strain is used). The tensile component is rather small but always exists. 

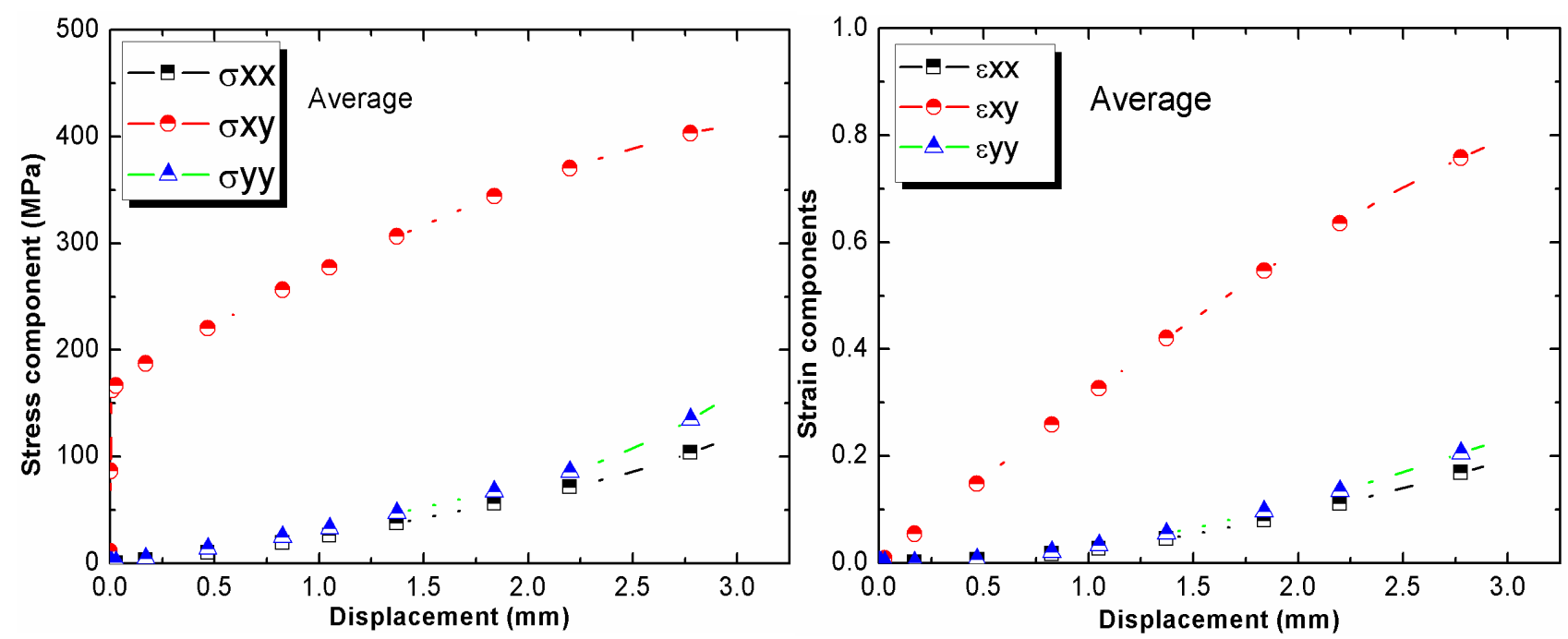

Fig. 5. Average value of stress and strain components

It should be also noted that the state of strain and stress is never homogeneous because of the free boundary conditions. Fig.6 illustrates the strain and stress contour at two different displacement levels.
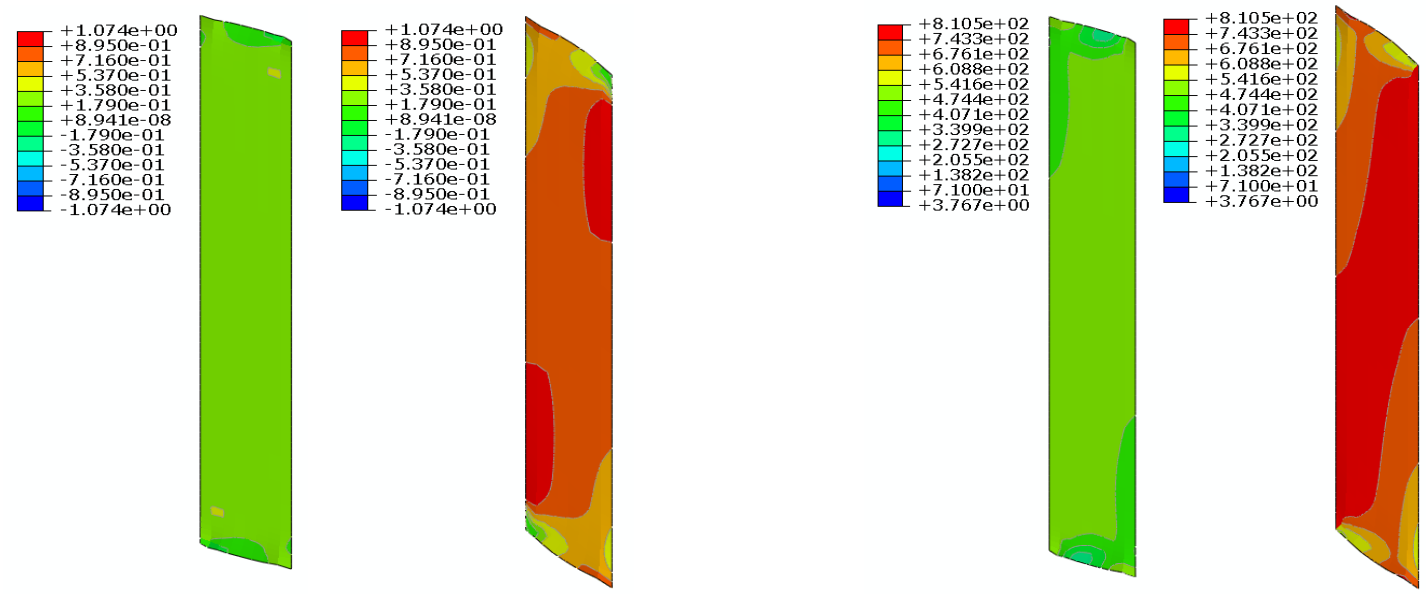

Figure 6 Strain (left) and stress (right) contours at displacements of $1 \mathrm{~mm}$ and $3 \mathrm{~mm}$

More precisely, Fig. 7 shows the average value of the equivalent stress and the equivalent strain of all the elements in the lines at the top surface, at a distance of $1.25 \mathrm{~mm}$ and $2.5 \mathrm{~mm}$ from the top free surface and at the center (see Fig. 4a) in the case of a shear area length of $20 \mathrm{~mm}$. 

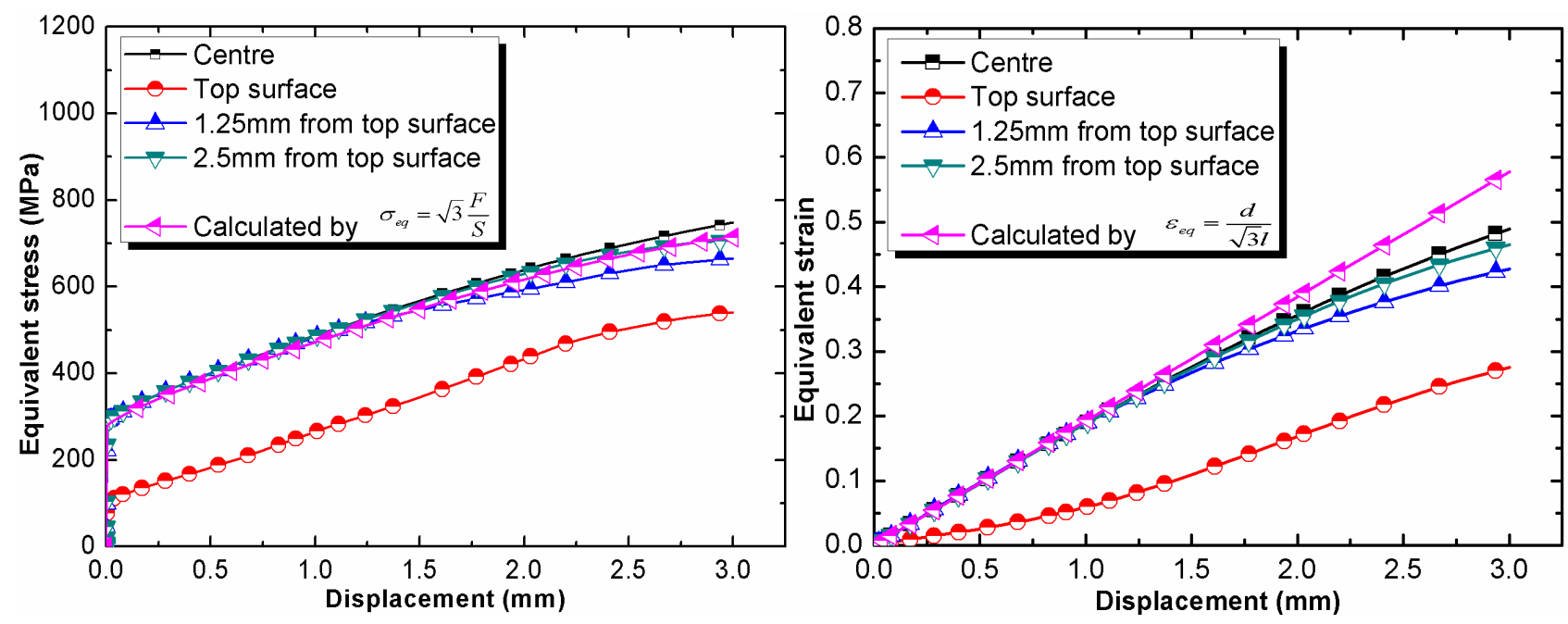

Fig. 7. Equivalent stress and strain at different locations

Such gaps from idealized homogeneous stress/strain fields assumption cannot be avoided neither. Even though a long specimen length of $120 \mathrm{~mm}$ (6 times) is used, the overall error will not be significantly reduced. Fig. 8a provides an overall comparison between the numerically calculated force (scaled with length ratio) and the prescribed force obtained by applying the eq. (4) to the prescribed constitutive relation. The relative error can be defined and depicted in Fig. 8b, where the improvement is rather limited.

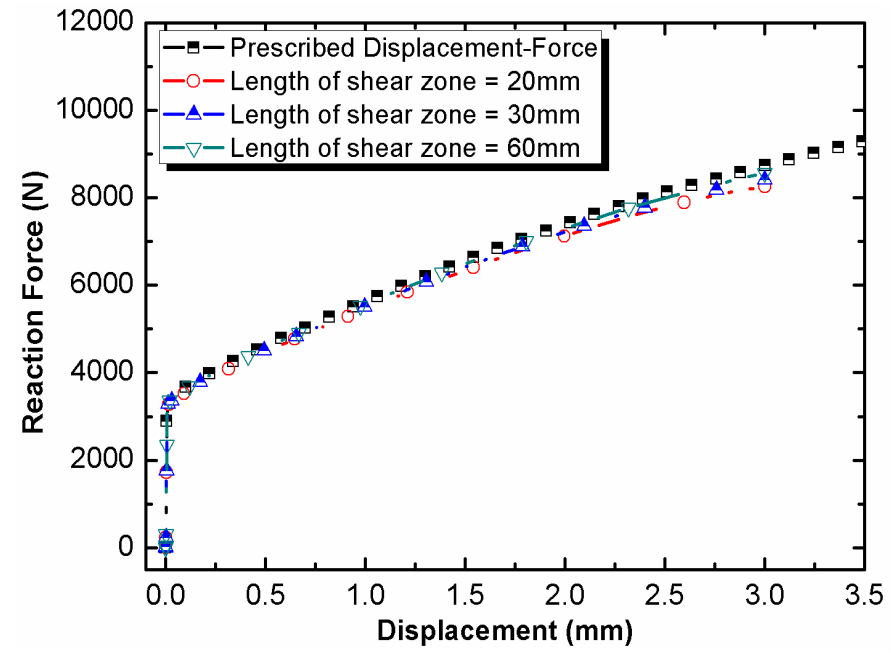

(a)

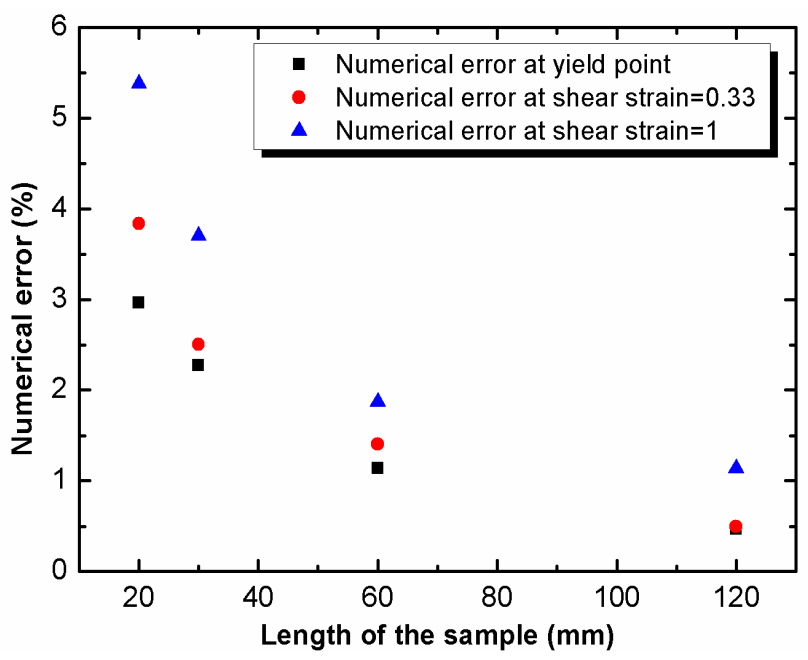

(b)

Fig. 8 Forces and numerical errors for different lengths of shear zone 
Consequently, $20 \mathrm{~mm}$ or $30 \mathrm{~mm}$ length are often adopted and the corrective coefficients are used to fill in the gaps. Fig. 9 depicts respectively the numerical average equivalent stress compared with nominal stress calculated by Eq. (4) and the average numerical equivalent strain compared with nominal strain (Eq. (3)). It seems that the commonly used corrective coefficient for stress is not needed if the average equivalent stress in the whole specimen is used instead of equivalent stress at the central part of the specimen (see also Fig. 7 left). However, a multiplying coefficient applied to nominal strain seems to be necessary.
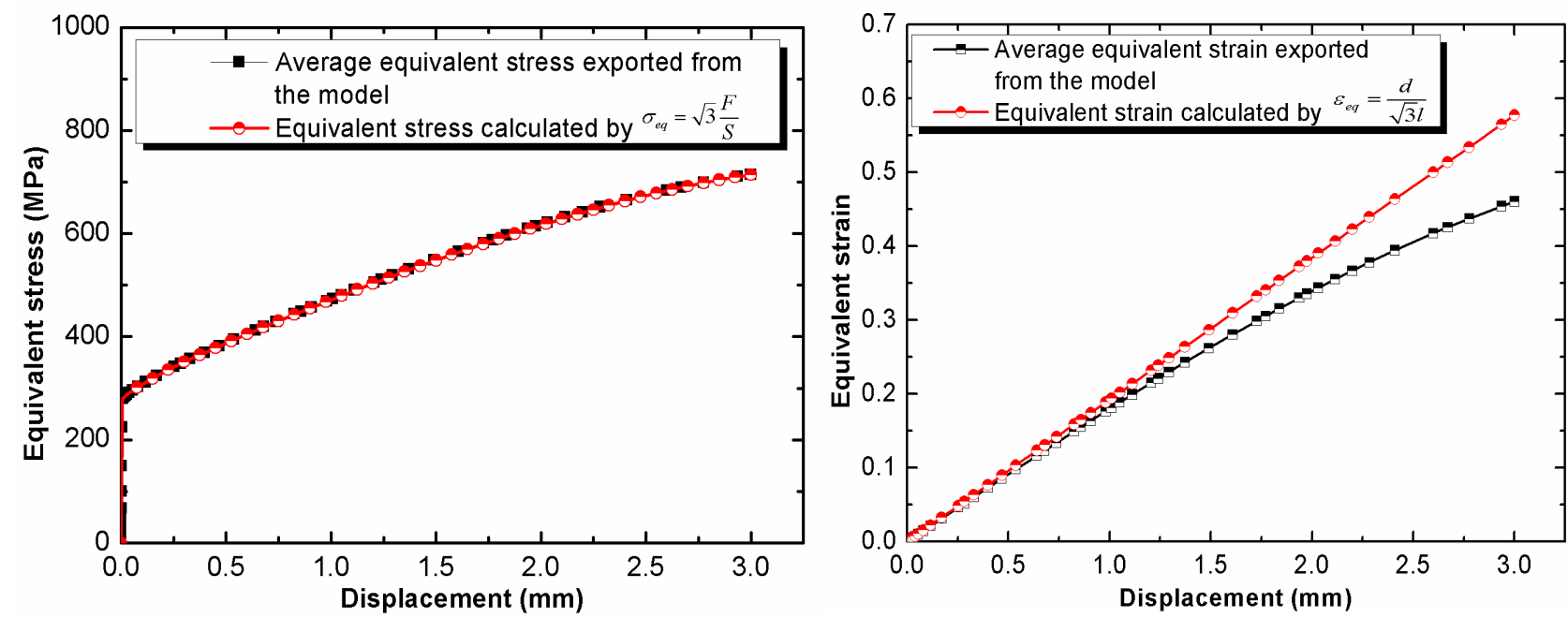

Fig. 9. Comparison between numerical results and nominal stress and strain

It is interesting to remark that FEM calculated strain has a significant gap from the idealized small strain shear assumption (Eqn2 and 3) while the FEM calculated stress fit with Cauchy stress (Eqn.4). Besides, simulations with different strain hardening behavior showed the same tendency. It is because the stress increase is limited by plastic behavior. Therefore, The studied case in this manuscript is rather a conservative one because lower strain hardening will lead to an even small difference in stress.

\section{Numerical analysis of the influence of the clamping device}

From aforementioned analysis, the corrective coefficients include the eventual imprecision of the used numerical model. An evident source of numerical errors lies in the ignorance of the clamping device. A complete model including grips as well as the specimen is then built. In order to minimize the influence of the contact, the fixing bolts in all clamping pieces are not taken into account. An overall view of the FEM model is shown in Fig. 10. The convergence study on element size indicates that elements of $0.4 \mathrm{~mm}$ in the shear area are small enough to achieve the reliable results 
within an acceptable calculation time.

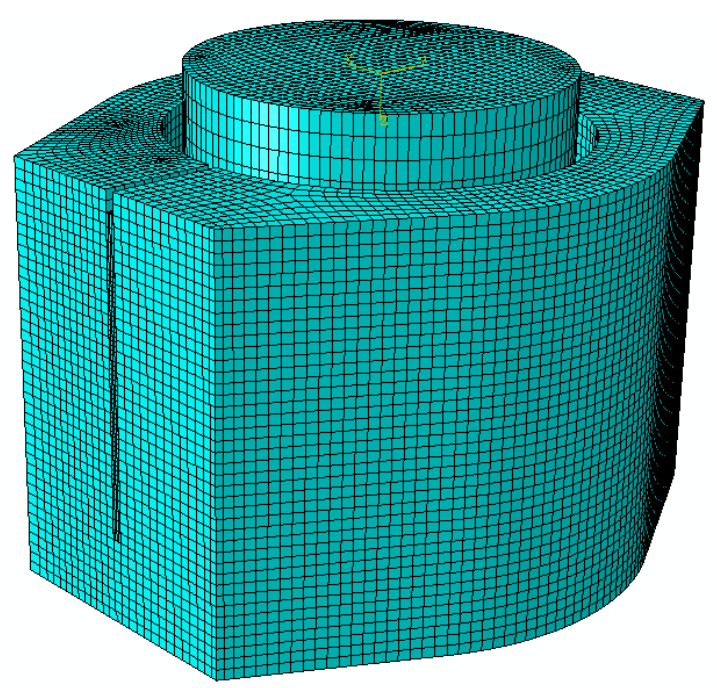

Fig. 10. Complete numerical model

\subsection{Quasi-static testing}

For the quasi-static simulation, the external clamps are fixed for all nodes situated at the bottom surface. A constant velocity of $0.001 \mathrm{~mm} / \mathrm{s}$ is prescribed on the top surface of the inner clamp. Surface-to-surface contact with penalty contact method is used for all the contact faces between the specimen and clamps. No slip is allowed between the two grips and the specimen.

Fig. 11a and Fig. 11b give the contour plots of the equivalent von-Mises stress and the shear strain at two nominal strain levels corresponding to a displacement of $1 \mathrm{~mm}$ and $3 \mathrm{~mm}$. They can be compared with the results obtained with the simple model presented in the section 2 (superimposed in the central part of the specimen). One can see that the shapes and values between those two models are nearly the same, which indicates a limited influence of the clamps.

It is worthwhile to notice that the strain contour plot outside the rectangular shear zone is due to the deformation of clamping pieces because of the clamping reaction forces. It means that the clamping pieces undergo a deformation that results in a less rigid boundary condition. 


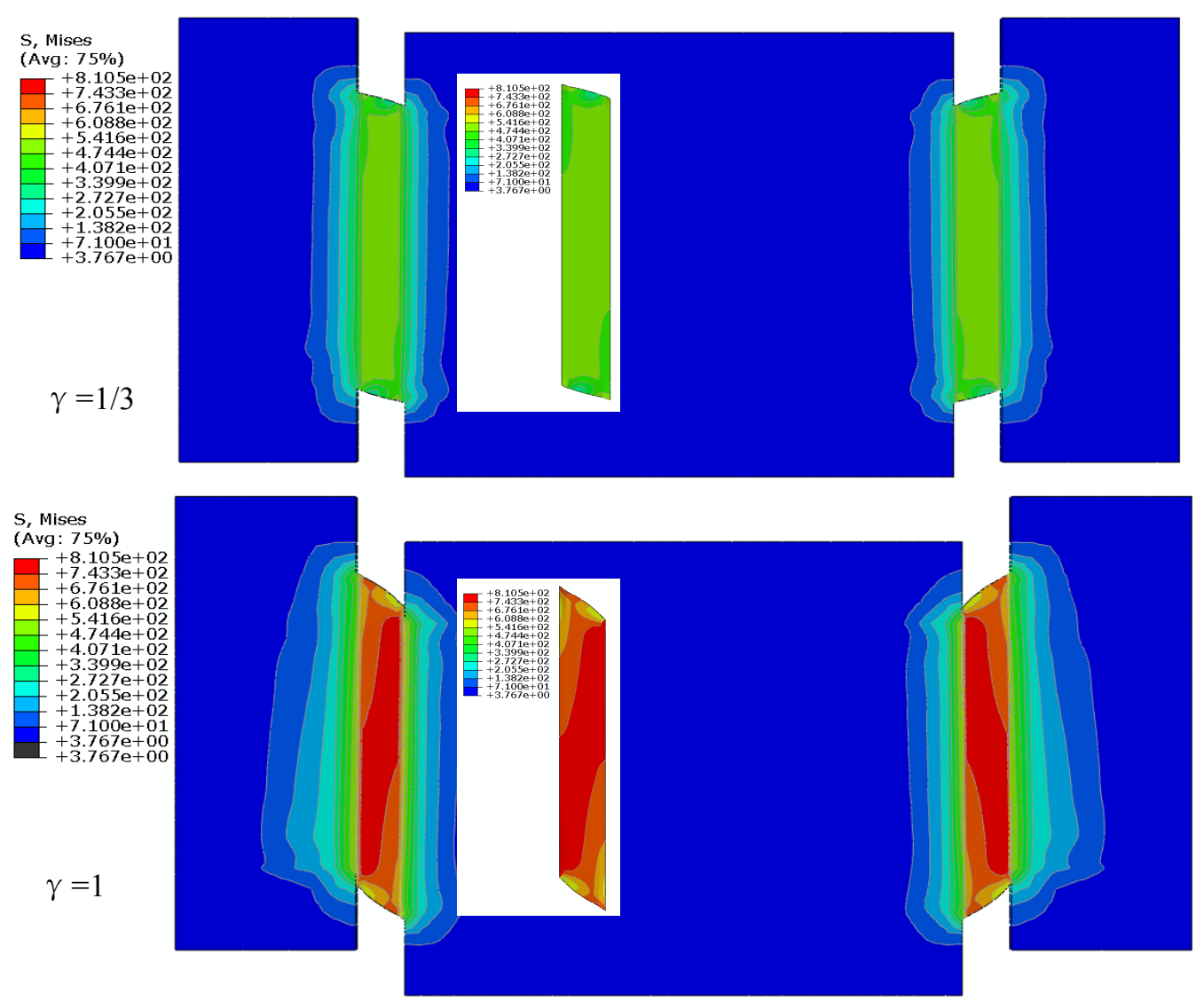

Fig. 11a. von Mises stress comparison between the simple model and complete model

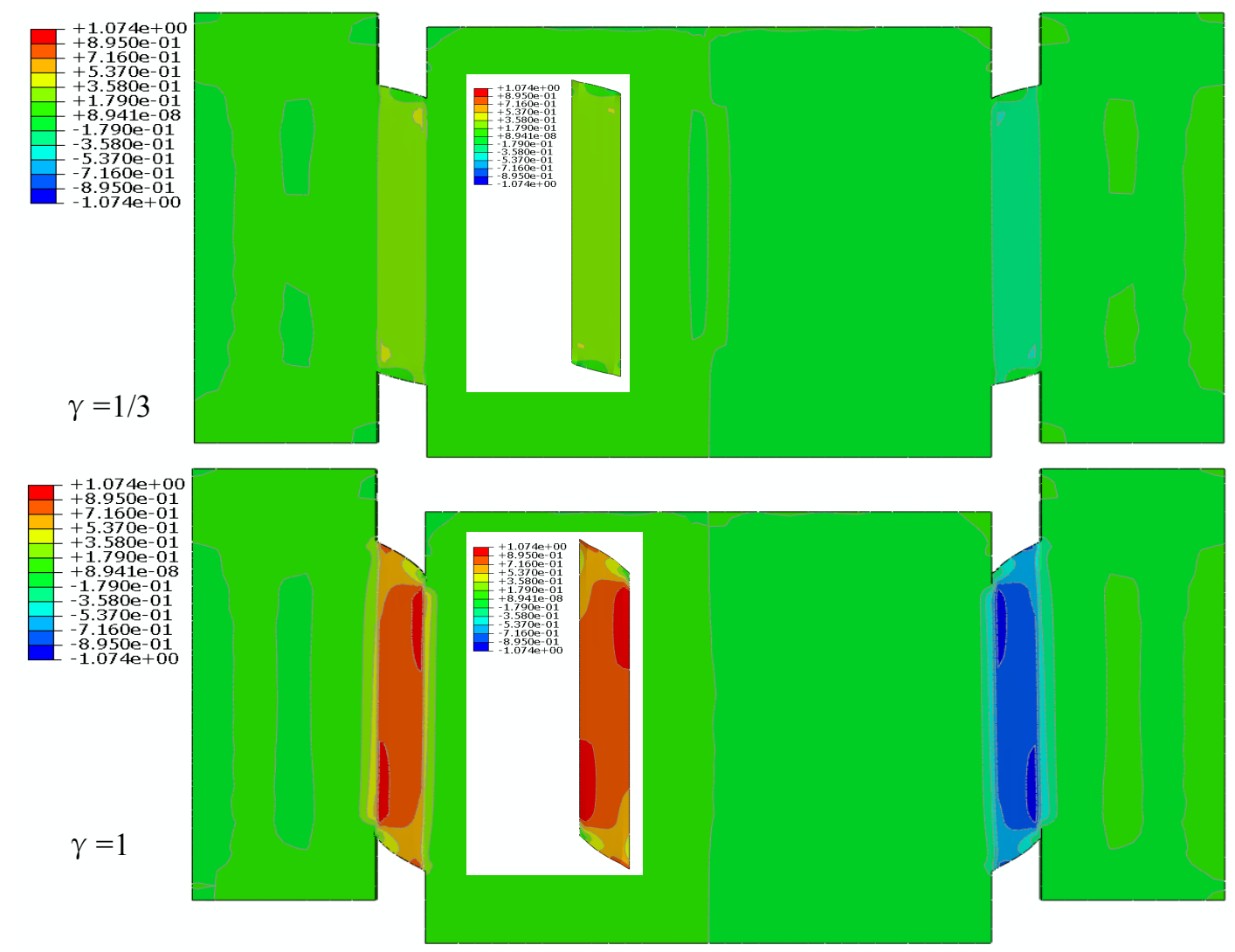

Fig. 11b. Shear strain comparison between the simple model and complete model 
The detailed quantitative comparison between the simple rigid model and the complete model are also depicted in Fig. 12. At different places in the specimen, all the components seem only have negligible difference.
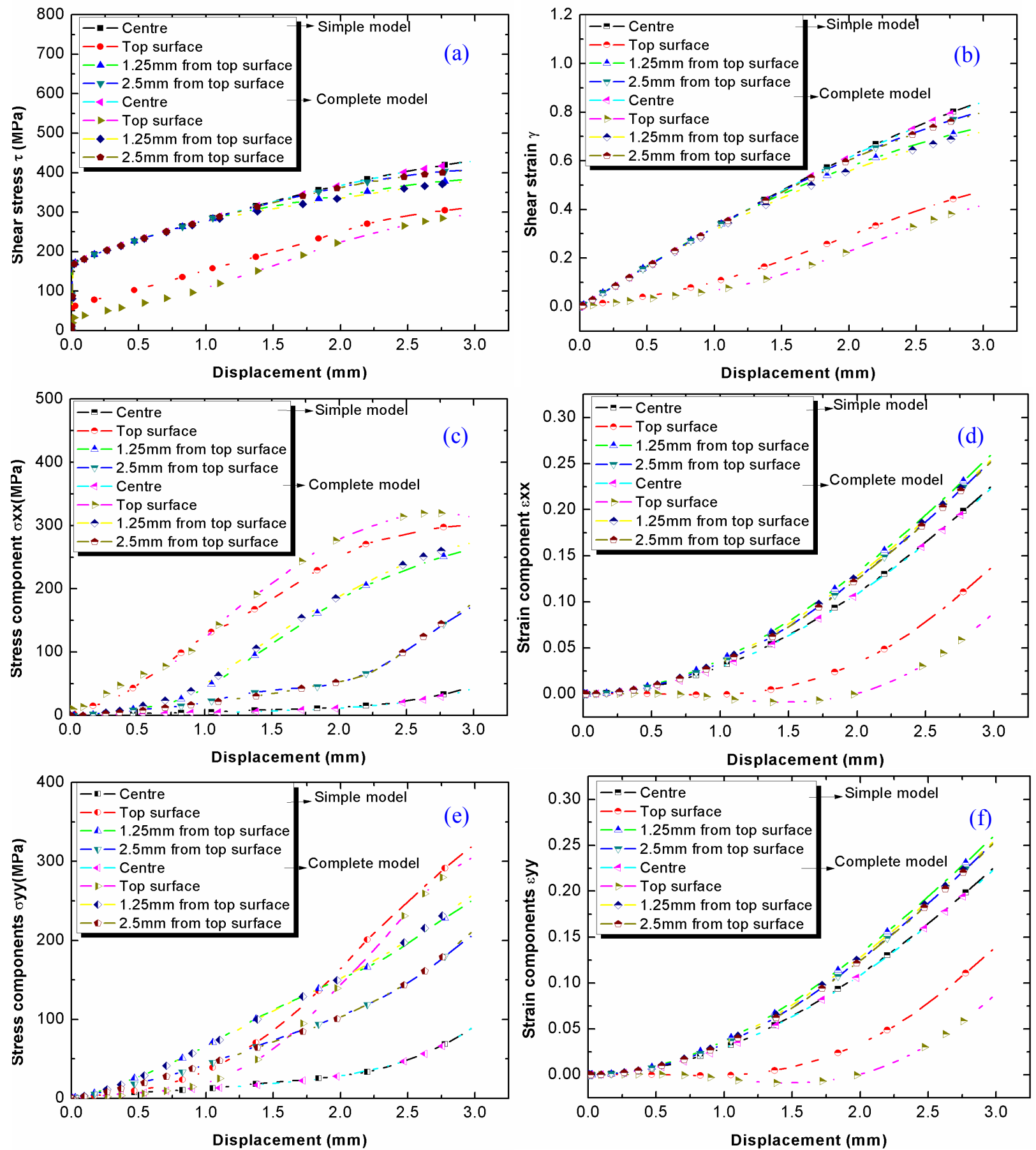

Fig. 12. Comparison between the simple model and complete model of the stress components (a),(c),(e) and strain components (b),(d),(f) of different positions of the shear zone 
If we compare the numerical result with the prescribed force, the result of simple model agrees well with that of complete model. However, at rather small strain, the two models differ because of stiffness exaggeration of clamping pieces in the simple model. This leads naturally to different slopes of the elastic stage (see Fig. 13).
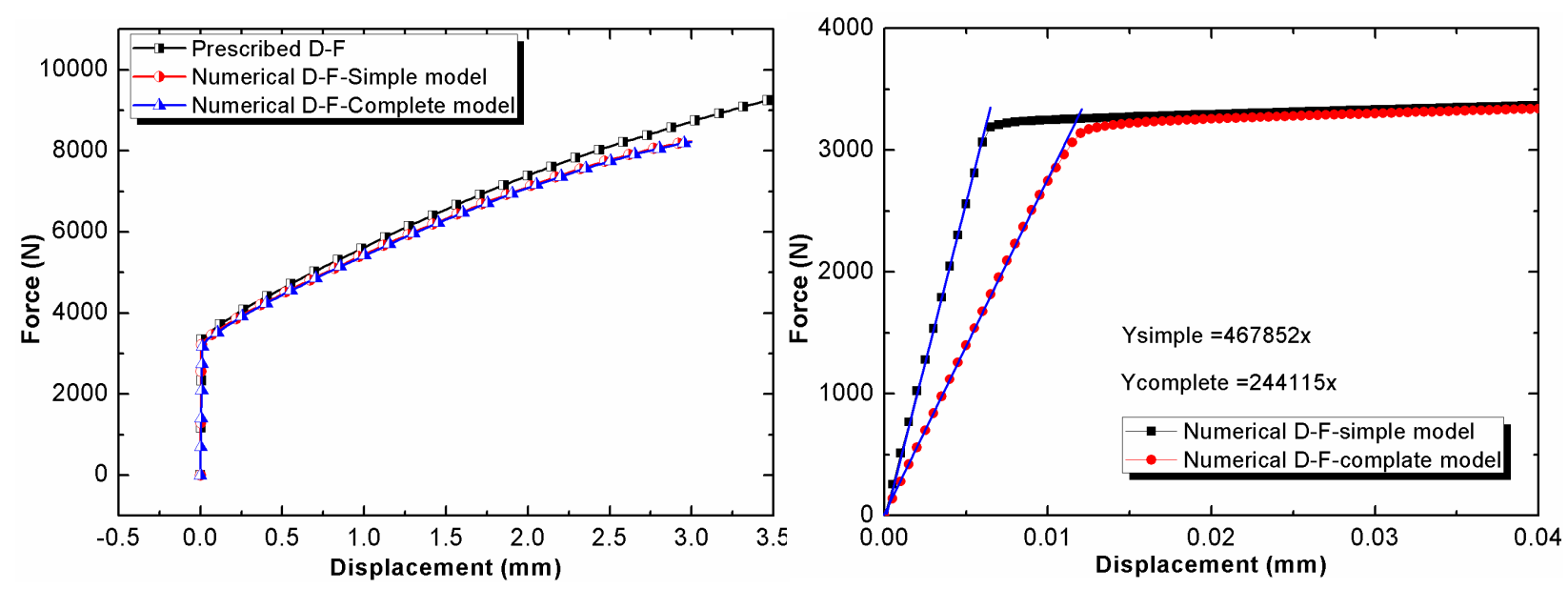

Fig. 13. Overall comparisons between the simple model and complete model

\subsection{Impact testing}

Numerical analysis of the complete model under impact loading is performed with Abaqus/explicit. The material parameters (rate insensitive) and element size are the same as that of quasi-static case. Input and output velocities measured in a real SHPB test are prescribed at the two opposite ends of clamping device (see Fig. 14). The input velocity is under $3 \mathrm{~m} / \mathrm{s}$, which is rather small for a classical SHPB. However, it leads to a shear strain rate around $1000 \mathrm{~s}^{-1}$ because the gage length (width) in the shear configuration is only $3 \mathrm{~mm}$. 


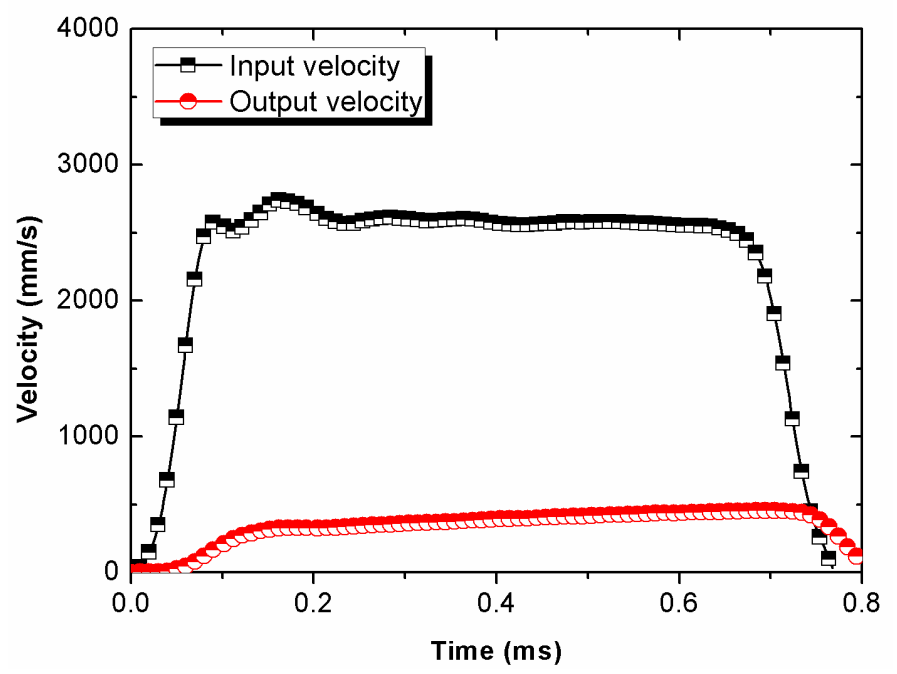

Figure. 14. The prescribed velocities

The average value of stress components (Fig. 15a) and strain components (Fig. 15b) under impact is compared with these values under quasi-static loading. It indicates that the effect of clamps is very small in the shearing area. The detailed comparison at different positions of all the components in these two loading cases shows that the stress and strain distributions are nearly the same (Fig. 16).

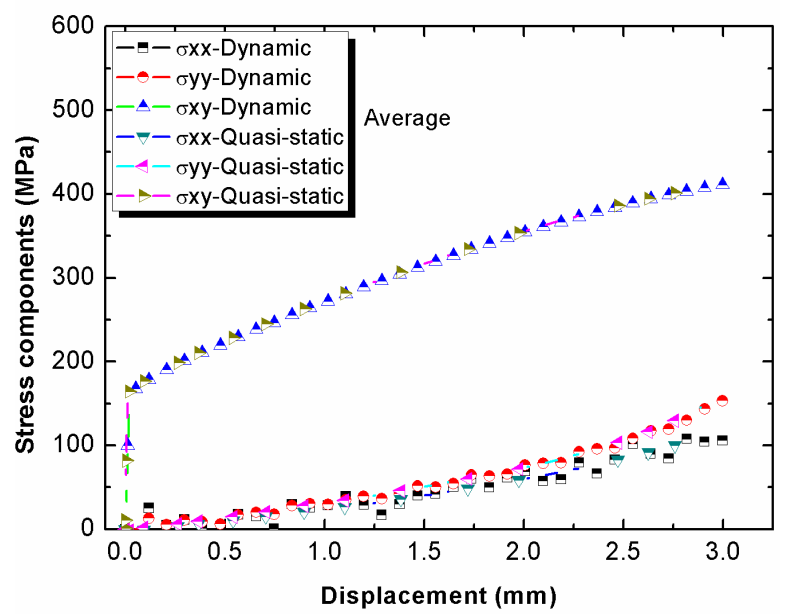

(a)

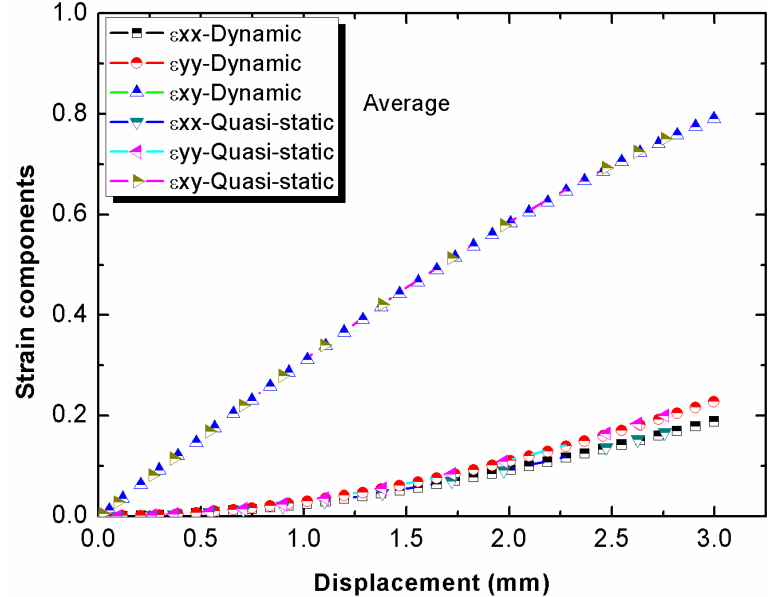

(b)

Figure 15. Stress and strain components for quasi-static and dynamic models 

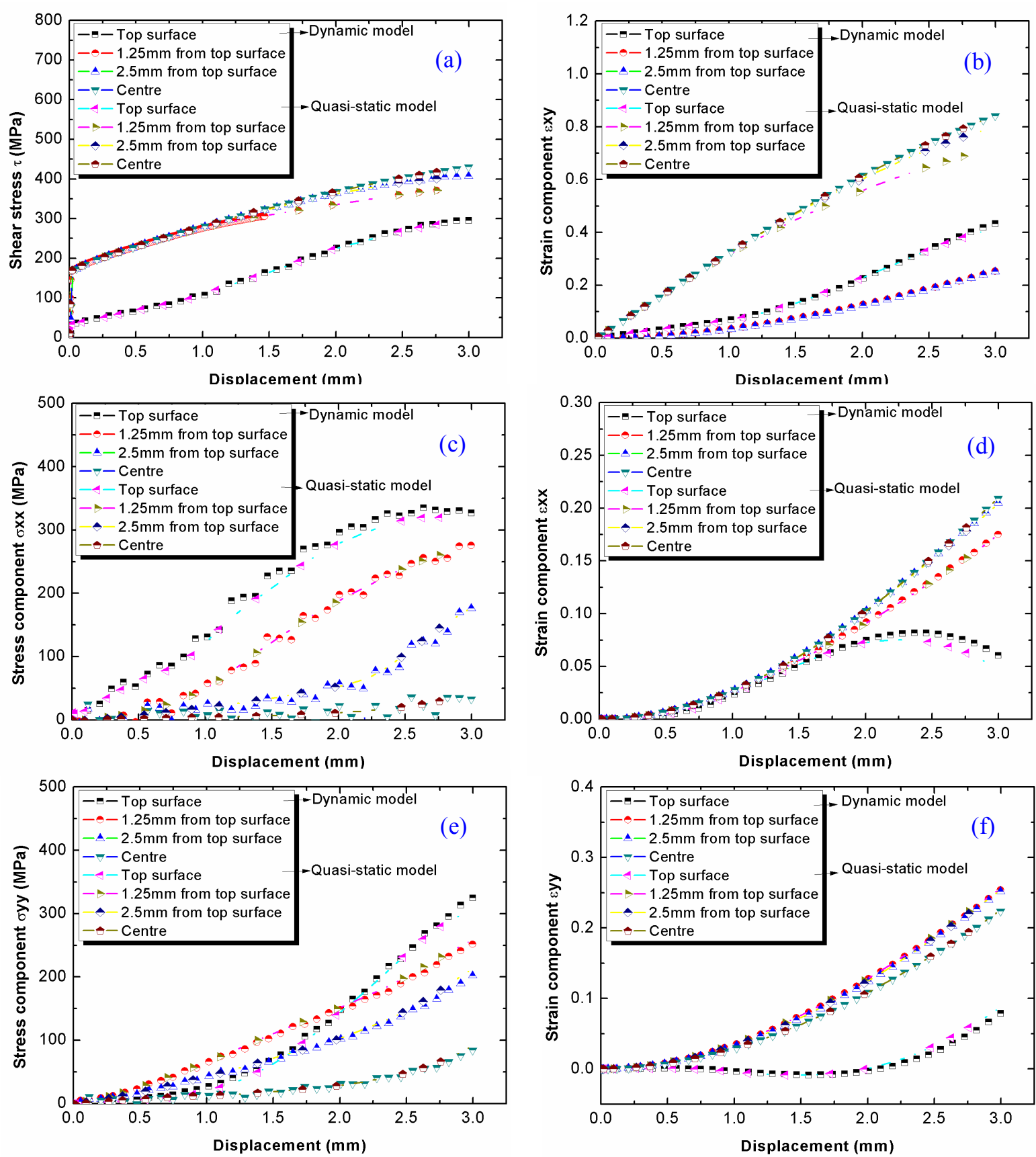

Fig. 16. Comparison between the quasi-static model and dynamic model of the stress components (a),(c),(e) and strain components (b),(d),(f) of different positions of the shear zone

Above simulated results imply that the transient effect inside the shear area of the specimen is negligible and a somehow equilibrium state has achieved quite quickly. Fig. 17 illustrates this process inside the specimen. 


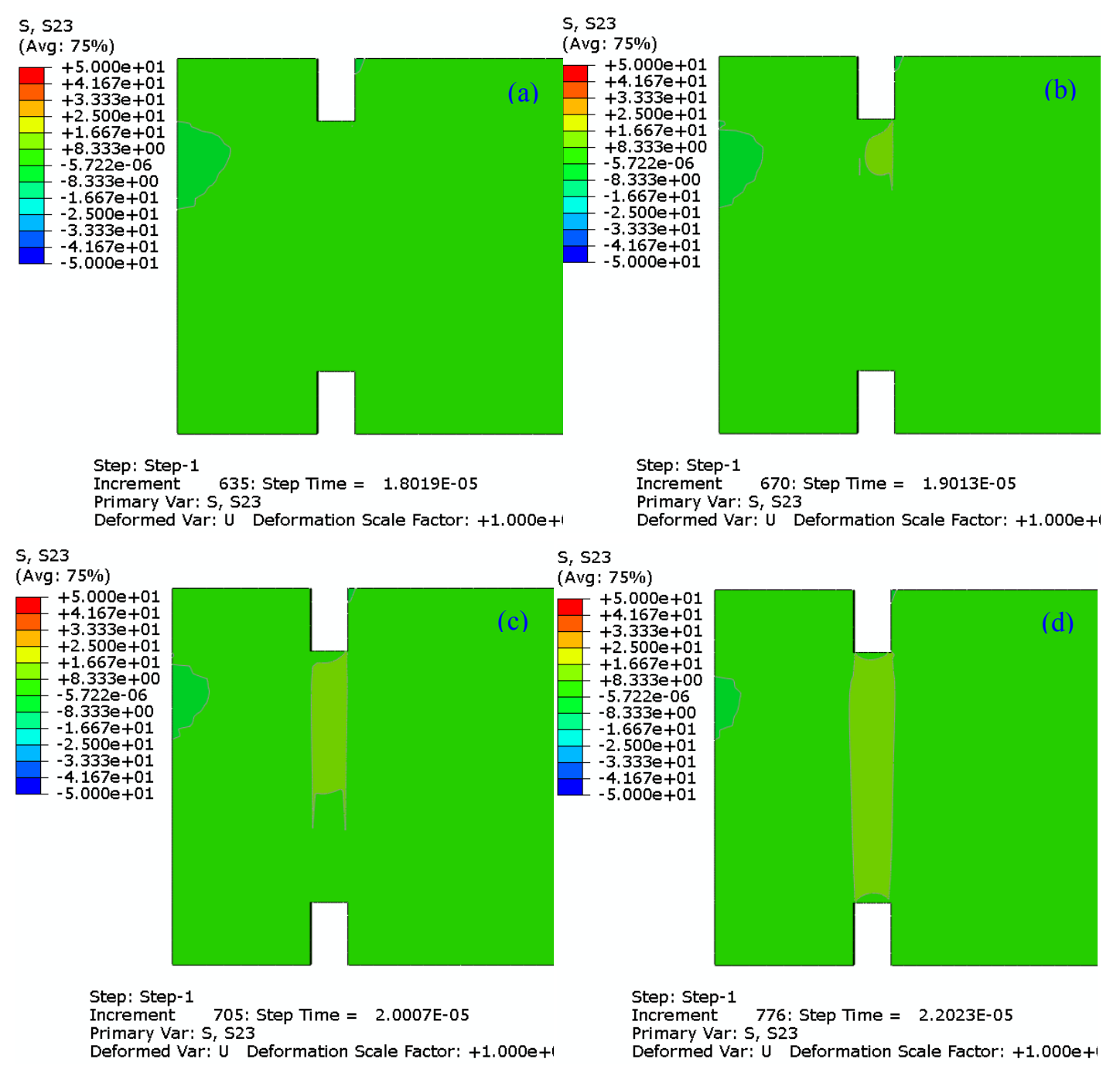

Fig. 17. The contour plot of shear stress on the shear zone at different moments

It can be seen in Fig. 17 that at 18 microseconds (a), the specimen is not yet loaded. At 19 microseconds (b), the shear start from corner in contact with the inner grips propagating not only horizontally towards the external grips by the shear wave but also vertically along the inner grips because of the compressive wave within the massive inner grips. At 20 microseconds (c), it is clear that the compressive wave in inner grips is dominant. At 22 microseconds (d), all the shear area is nearly homogeneous. Within 4 microseconds which is the time needed for the compressive wave to pass through the $20 \mathrm{~mm}$ length of the shear area, the shear area is likely to be loaded homogeneously. Such processes repeat during the rising time of prescribed velocity (40 microseconds, see Fig. 14). This may explain why the stress and strain fields within shear area are hardly affected by the impact loading.

Unfortunately, such a quick equilibrium state does not mean that the transient effect in the clamping pieces is not important. Fig. 18 illustrates the compressive wave propagating in the inner 
grips as an example. The wave needs more than 6 microseconds to go through the clamping pieces.
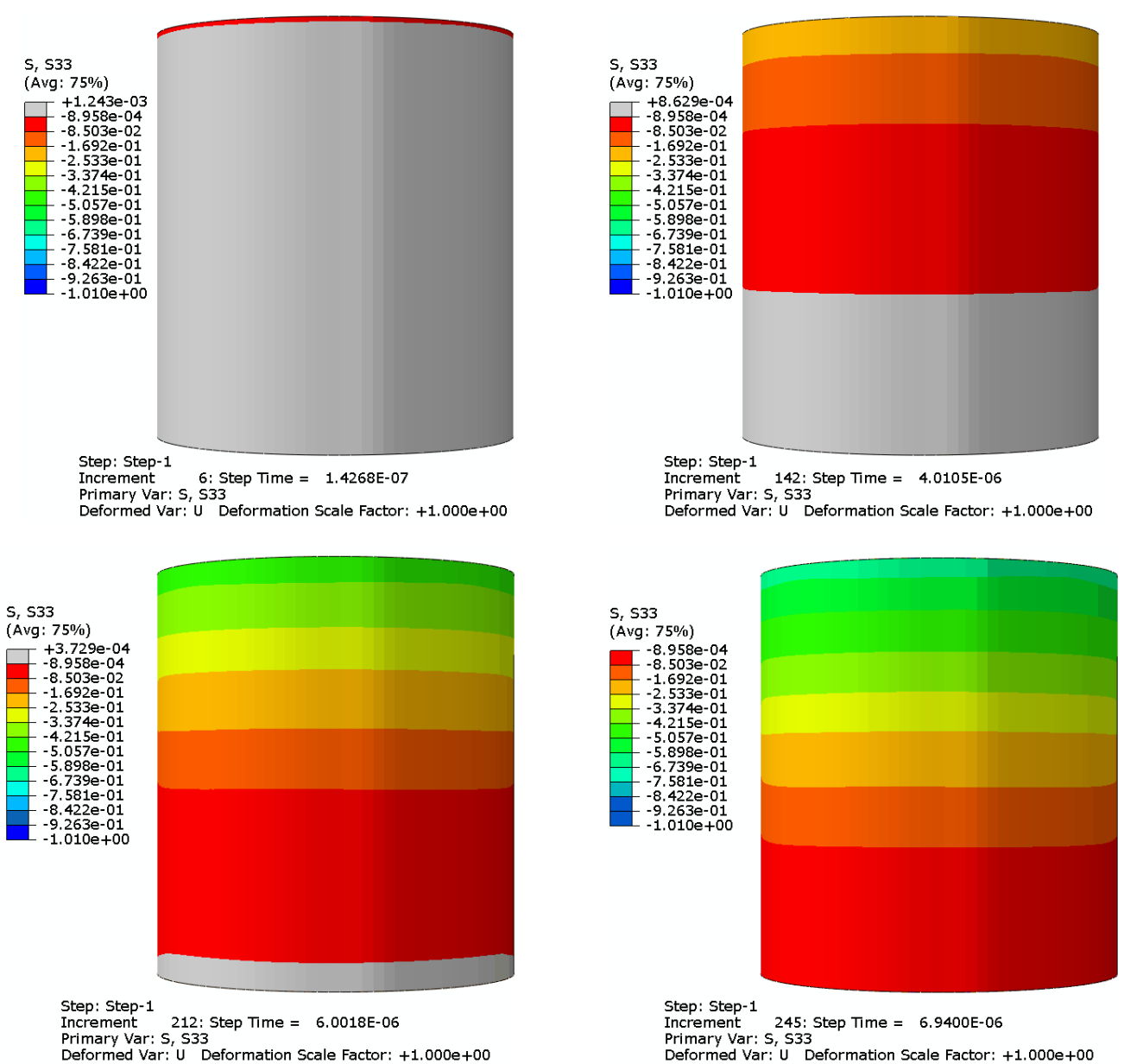

Fig.18. Contour plot of compression wave stress marching on the inner clamp

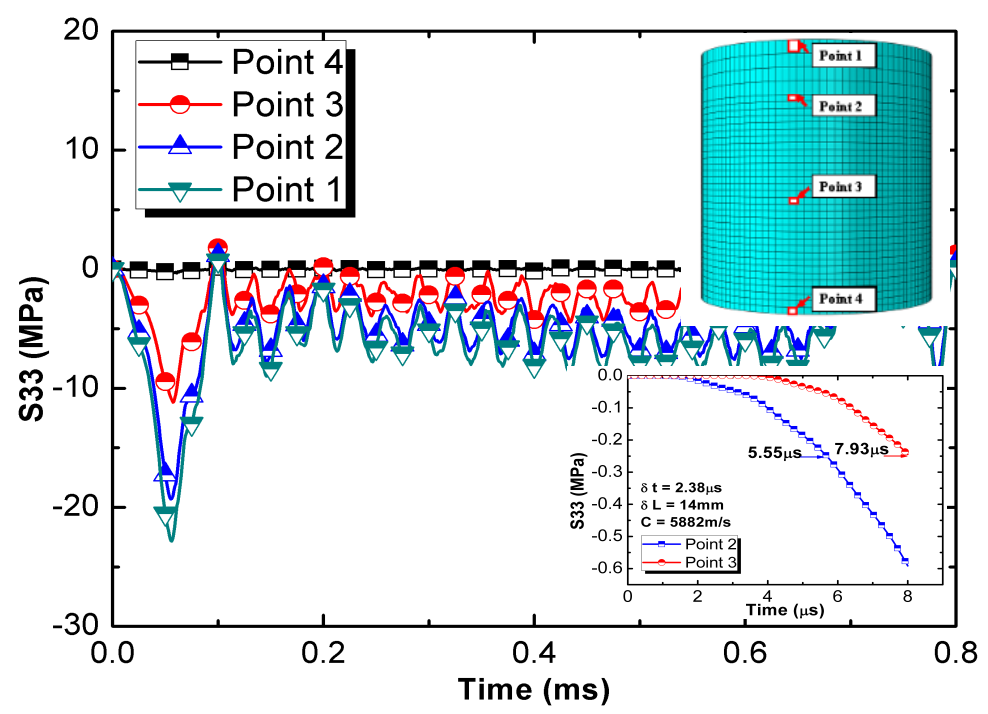

Fig.19. Compression wave stress on four nodes of outer surface of the inner clamp

Fig. 19 depicts the stress time histories at different positions of the inner grips. Point 4 is the 
free surface so that the stress is zero. Point 1 is the place where the input force is calculated. As the other points, oscillations are found during all the testing time. There are roughly 7 periods in 200 microseconds. A round trip is likely to be made in about 28 microseconds. The time delay between different points can give a more accurate evaluation of the compressive wave speed. A value of $5882 \mathrm{~m} / \mathrm{s}$ is found and it matches roughly the waves speed in a short cylinder (Fig. 19). Therefore, a round trip of 28 microseconds corresponds to a distance of $164 \mathrm{~mm}$, which is roughly the distance of a round trip inside inner and external grips $(2 \times(40+40) \mathrm{mm})$.

In order to further prove that this oscillation is due to the wave traveling within the clamps, a simulation for the clamps with a Young's modulus 100 times high at $21000 \mathrm{GPa}$ is performed. The wave speed is then 10 times quicker. Fig. 20 shows the comparison of the two simulations as well as the prescribed force. One can see that the transient effect could dramatically affect the measured force. The input force cannot be used at all because of the wave superimposition. The output force is likely to be less affected because there is only a time shift. However, the early stage is more questionable. It is noted also that the important spurious oscillations is surely exaggerated in the numerical model where all the contact is hard. In the real test, such oscillation is not observed, likely to be mechanically absorbed.

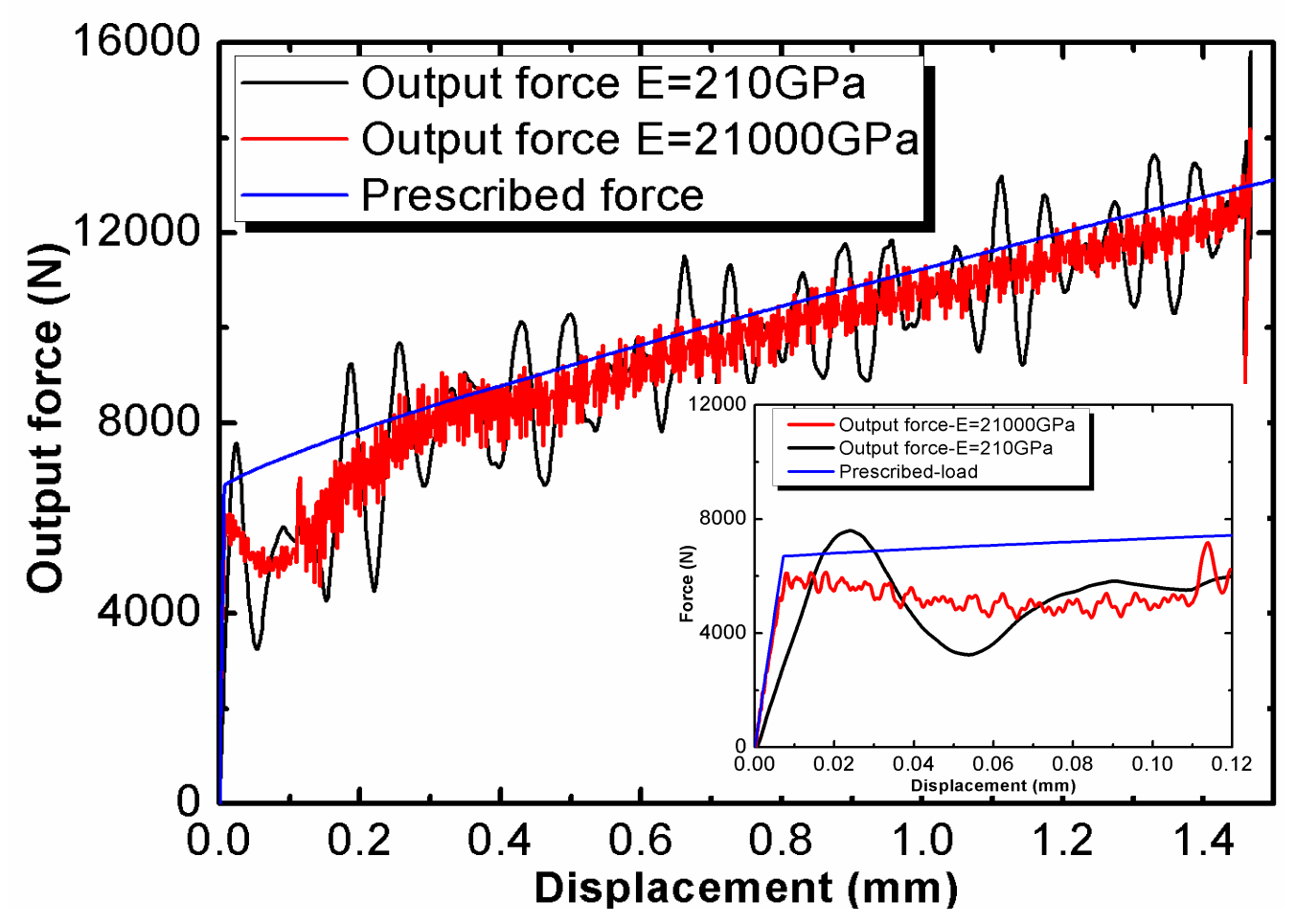

Fig. 20. Comparison of output force with different young's modulus defined 
The above analysis of transient effect in this plane shear tests provides a guideline for the data extracting procedure. Indeed, as the compressive wave in the clamping pieces is dominant and these clamping cylinders have the same impedance as the pressure bar, they can be considered as a part of the Hopkinson bar. Thus, we considered the case is just like in a common SHPB with additional length (length of the clamping device) with a very small specimen.

\section{Large strain definition used in FEM codes and strain corrective coefficient}

As mentioned in the introduction, the corrective coefficients include not only the error of numerical model but also the error in the way that the nominal stress and strain are calculated. It is natural to ask whether the Eqs. (3 and 4) are the best way to calculate the nominal strain and stress, especially at high strain levels? Actually, the default strain definition in most FEM codes and in all the explicit codes (at least for 3D brick elements) is the cumulated Eulerian strain obtained by integrating the symmetric part of velocity gradient. If there is a rotation or precisely vorticity, which is the case of plane shear testing, this integration should be made in a corotational frame where the vorticity is zero to ensure the objectivity of the cumulated strain [18]. As the constitutive relation are naturally used in the FEM code, it is important to formulate and experimentally identify such a relation using the same stress and strain definition. The following theoretical analysis provides the formulas to calculated this Eulerian cumulated strain from displacement d (Fig. 3) directly measured during testing. Besides, this analysis demonstrates also why the tension part becomes more and more important (shown in Fig.5).

Actually, if we take a fixed reference frame $\mathrm{R}\left(\vec{x}_{1}, \vec{x}_{2}, \vec{x}_{3}\right)$ as shown in Fig. 3, the velocity field in plane shear testing reads:

$$
\vec{V}_{\mid R}=\left(\begin{array}{c}
0 \\
\dot{\gamma} x_{1} \\
0
\end{array}\right)
$$

where $\gamma=\mathrm{d} / l$ is engineering shear strain.

The velocity gradient can be expressed as a sum of its symmetric part, the rate of deformation $\mathrm{D}$, and its anti-symmetric part, the vorticity $\Omega$ : 


$$
\operatorname{grad} \vec{V}_{\mid R}=\left(\begin{array}{ccc}
0 & 0 & 0 \\
\dot{\gamma} & 0 & 0 \\
0 & 0 & 0
\end{array}\right)=\left(\begin{array}{ccc}
0 & \dot{\gamma} / 2 & 0 \\
\dot{\gamma} / 2 & 0 & 0 \\
0 & 0 & 0
\end{array}\right)+\left(\begin{array}{ccc}
0 & -\dot{\gamma} / 2 & 0 \\
\dot{\gamma} / 2 & 0 & 0 \\
0 & 0 & 0
\end{array}\right)=D_{\mid R}+\Omega_{\mid R}
$$

The vorticity in this frame is then not zero. The cumulated Eulerian strain can not be calculated in this frame. In order to find the needed frame without vorticity, we rotate $\mathrm{R}\left(\vec{x}_{1}, \vec{x}_{2}, \vec{x}_{3}\right)$ around $\vec{x}_{3}$ with an angle $\theta(\mathrm{t})$ to define a new reference frame $R^{\prime}\left(\vec{x}_{i}, \vec{x}_{j}, \vec{x}_{3}\right)$. Thus, the velocity field in this new frame can be expressed in the coordinate system $\left(\vec{x}_{i}, \vec{x}_{j}, \vec{x}_{3}\right)$ as :

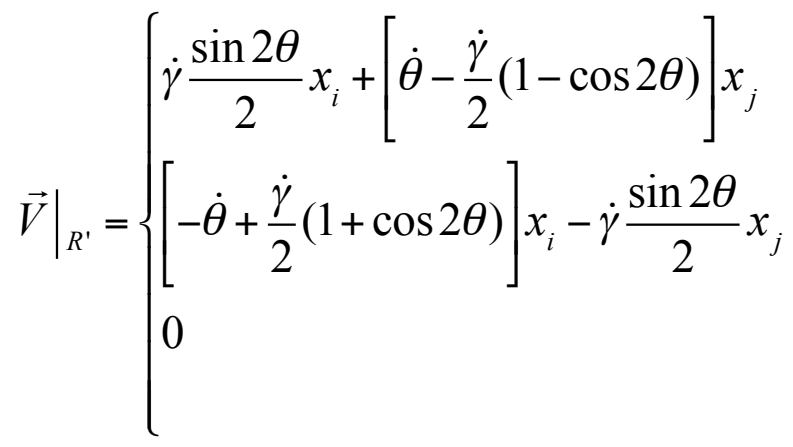

The rate of deformation $\mathrm{D}$ and vorticity $\Omega$ in this rotating frame is calculated by:

$$
\left.D\right|_{R^{\prime}}=\left.\left[\begin{array}{cc}
\dot{\gamma} \frac{\sin 2 \theta}{2} & -\dot{\gamma} \frac{\cos 2 \theta}{2} \\
-\dot{\gamma} \frac{\cos 2 \theta}{2} & -\dot{\gamma} \frac{\sin 2 \theta}{2}
\end{array}\right] \Omega\right|_{R^{\prime}}=\left[\begin{array}{cc}
0 & \dot{\theta}-\frac{\dot{\gamma}}{2} \\
\frac{\dot{\gamma}}{2}-\dot{\theta} & 0
\end{array}\right]
$$

As we aim at finding a reference frame where the vorticity should be zero, this angle $\theta(\mathrm{t})$ should satisfy

$$
\theta=\theta_{0}+\frac{\gamma}{2}
$$

Thus, the rate of deformation and vorticity are calculated in this specific reference frame $R^{s}$. 
$\left.D\right|_{R^{s}}=\left.\left[\begin{array}{cc}\dot{\gamma} \frac{\sin \left(2 \theta_{0}+\gamma\right)}{2} & -\dot{\gamma} \frac{\cos \left(2 \theta_{0}+\gamma\right)}{2} \\ -\dot{\gamma} \frac{\cos \left(2 \theta_{0}+\gamma\right)}{2} & -\dot{\gamma} \frac{\sin \left(2 \theta_{0}+\gamma\right)}{2}\end{array}\right] \Omega\right|_{R^{s}}=0$

By integrating $\left.D\right|_{R^{s}}$ with time t, the strain tensors in $R^{s}$ can be found:

$$
\left.E^{s}\right|_{R^{s}}=\left[\begin{array}{cc}
\sin \frac{\gamma}{2} \sin \left(2 \theta_{0}+\frac{\gamma}{2}\right) & -\sin \frac{\gamma}{2} \cos \left(2 \theta_{0}+\frac{\gamma}{2}\right) \\
-\sin \frac{\gamma}{2} \cos \left(2 \theta_{0}+\frac{\gamma}{2}\right) & -\sin \frac{\gamma}{2} \sin \left(2 \theta_{0}+\frac{\gamma}{2}\right)
\end{array}\right]
$$

The projection of strain tensor to the coordinate system $\left(\vec{x}_{1}, \vec{x}_{2}, \vec{x}_{3}\right)$ it leads to

$$
\left.E^{s}\right|_{R}=\left[\begin{array}{cc}
-\frac{1}{2}(1-\cos \gamma) & \frac{1}{2} \sin \gamma \\
\frac{1}{2} \sin \gamma & \frac{1}{2}(1-\cos \gamma)
\end{array}\right]
$$

Thus, for the simple plane shear test, the von-Mises equivalent strain for this Eulerian cumulated strain tensor will be the following:

$$
\varepsilon_{e q}=\sqrt{\frac{2}{3}(1-\cos \gamma)}
$$

Fig. 21 shows the comparison of the nominal equivalent strain calculated by (Eq. 12) with the numerical average equivalent strain. There is nearly no gap and this implies that the main gap is actually due to a misunderstanding of the strain definition in the FEM codes in the large strain configuration. It implies that the non-homogeneous state of strain is not the main factor of the gaps found in previous works. 


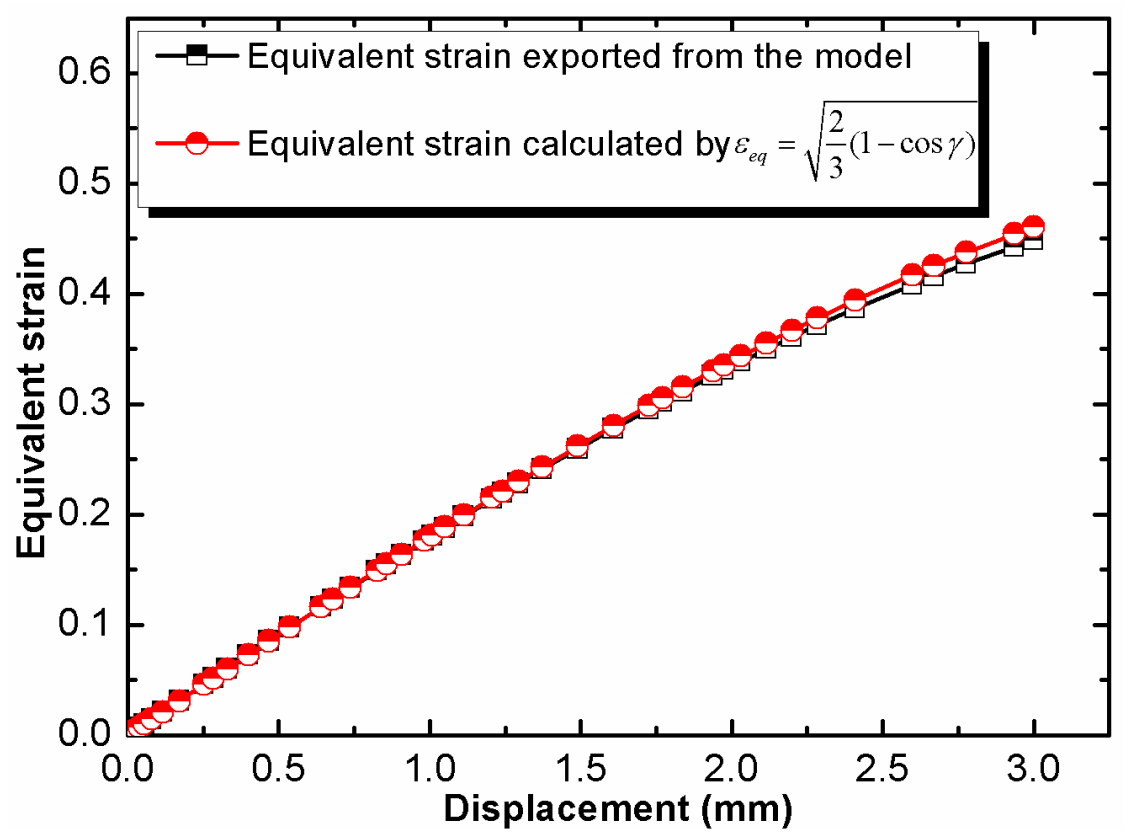

Figure.21. Numerical results compared with nominal strain

Finally, if the Euleiran cumulated strain is used to calculate nominal strain from experimental displacement data and the average equivalent stress in all the shear area is used, the corrective coefficients are no longer needed. Fig. 22 depicts the comparison between the prescribed force/displacement relation used to calculate prescribed stress-strain relation and the calculated force/displacement curve from the numerical model and they agree very well.

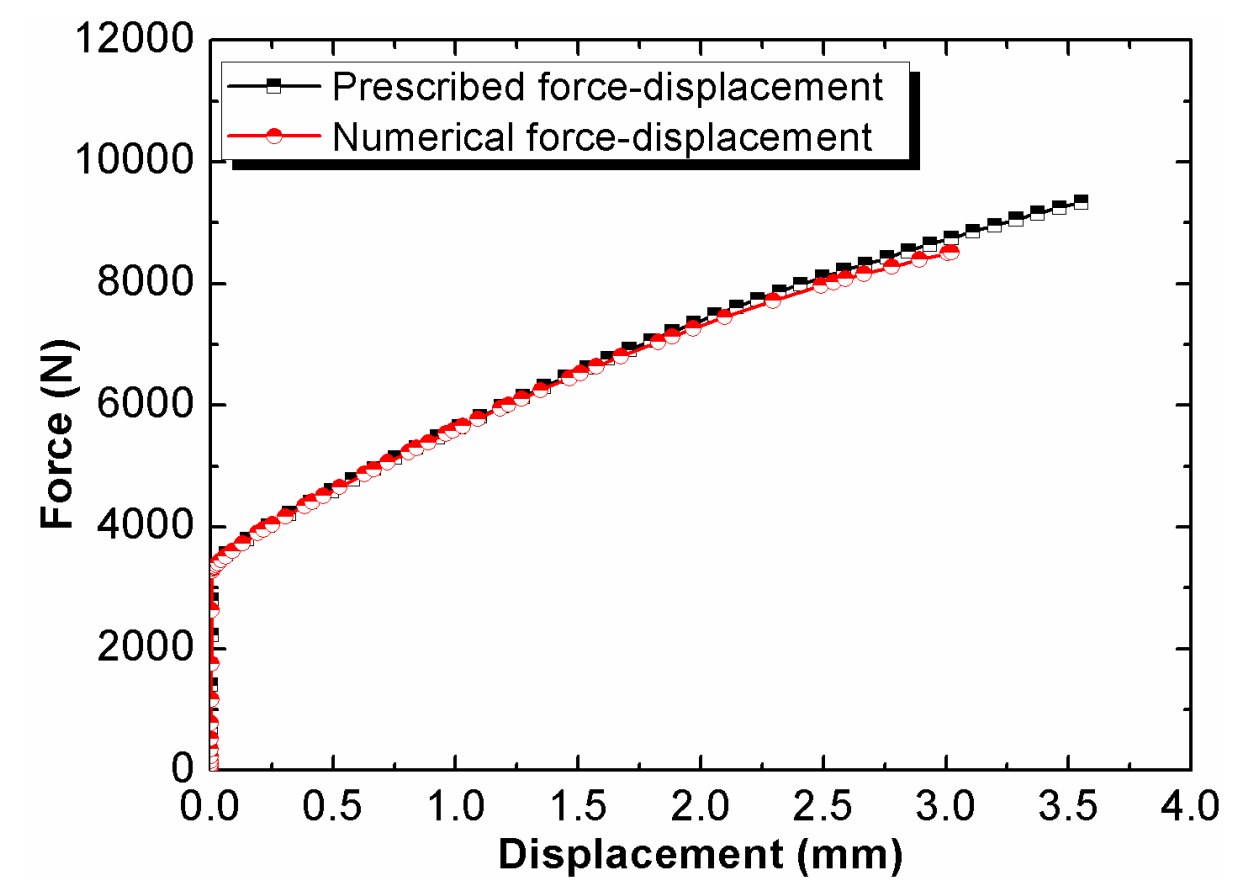

Fig. 22. Comparison of modified numerical result and experiment result 
The double shear tests for sheet metals are investigated numerically and analytically in this paper in order to understand and improve actual data extracting method. The main points are the following:

i) The clamping device has been added in the numerical model devoted to find commonly used corrective coefficients to extract stress-strain relation in such test. Under quasi-static loading, Taking account of the clamps leads to a less rigid boundary condition on the shear area. It leads to an additional error on the early stage of the test (elastic part).

ii) Under impact loading, the shear loading in the shear area is mainly guided by the compressive wave within the massive clamping pieces. The equilibrium within the shear area is quickly attained. However, the transient effect due to wave propagating between the clamping pieces leads to important oscillations.

iii) The cumulated Eulerian strain should be used to calculate the nominal strain in such test. With this cumulated Eulerian strain and Cauchy stress derived from experimental displacement/force recording, it is possible to repeat numerically the test. It implies that all the corrective coefficients commonly used for this test is no longer needed.

\section{Acknowledgement}

The authors acknowledge the support of China Scholarship Council (CSC) as well as NSFC funding no.11228206 and no. 11202168.

\section{References}

[1] N. Iosipescu, New accurate procedure for single shear testing of metals, J. MATER. 2(3) (1967) 537-566.

[2] C. G'sell, S.Boni, S.Shrivastava, Application of the plane simple shear test for determination of the plastic behaviour of solid polymers at large strains, J. Mater. Sci. 18(3) (1983) 903-918.

[3] F. Pierron, A.Vautrin, B. Harris, The losipescu in-plane shear test: validation on an isotropic material, Exp. Mech. 35(2) (1995) 130-136.

[4] M. Arcan, Z. Hashin, A. Voloshin, Method to produce uniform plane-stress states with applications to fiber-reinforced materials, Exp. Mech. 18(4) (1978) 141-146.

[5] K. Yoshida, K. Myauchi, Experimental studies of mechanical behavior as related to sheet metal forming, Mechanics of Sheet Metal forming, Plenum Press, New York, 1978, pp. 19-49.

[6] J. D. Campbell, W. G. Ferguson, The temperature and strain-rate dependence of the shear 
strength of mild steel, Philos Mag. 21(169) (1970) 63-82.

[7] J. Harding, J. Huddart, The use of the double-notch shear test in determining the mechanical properties of uranium at very high rates of strain, Proc. 2nd International Conf. Mechanical properties at high rates, The Institute of Physics, London, 1979, pp. 49-61.

[8] J. R. Klepaczko, Plastic shearing at high and very high strain rates, J. Phys. IV, 4(C8) (1994) C8-35-C8-40.

[9] G. Gary, W.K. Nowacki, Essai de cisaillement plan appliqué à des tôles minces. J. Phys. IV. 4(C8) (1994) C8-65-C8-70.

[10]R. Merle, H, Zhao, On the errors associated with the use of large diameter SHPB, correction for radially non-uniform distribution of stress and particle velocity in SHPB testing, Int. J. Impact Eng. 32(12) (2006) 1964-1980.

[11]J. R. Klepaczko, H. V. Nguyen, W. K. Nowacki, Quasi-static and dynamic shearing of sheet metals, Eur. J. Mech. A-Solid. 18(2) (1999) 271-289.

[12]A. Rusinek, J. R. Klepaczko, Shear testing of a sheet steel at wide range of strain rates and a constitutive relation with strain-rate and temperature dependence of the flow stress, Int. J. Plast. 17(1) (2001) 87-115.

[13]R. Merle, H. Zhao, Experimental study of sheet metals under dynamic double shear at large strains, Key Eng. Mater. 274 (2004) 787-792.

[14]Y. Guo, Y. Li, A novel approach to testing the dynamic shear response of Ti-6Al-4V, Acta. Mech. Solida. Sin. 25(3) (2012) 299-311.

[15]R. Merle, Mise en oeuvre et analyse d'un essai de double cisaillement en grandes déformations sous sollicitations dynamiques, Phd thesis, Laboratoire de Mécanique et Technologie, 2006.

[16]H. Zhao, Experimental characterisation of materials behaviour under dynamic loading, Computer \& structures. 81(2003), 1301-1310.

[17]F. F. Shi, H. Bing, Y. L. Li, J. Lu, H. Zhao, Experimental study on a graded stainless steel sheet under quasi-static and dynamic loading. Key Eng. Mater. 535 (2013) 56-59.

[18]P. Gilormini, P. Roudier, P. Rougée, Les déformations cumulées tensorielles, C. R. Académie. Sci. Sér. 316(11) (1993) 1499-1504. 